\title{
成都地铁 10 号线对机场陆侧流分担率预测
}

\section{Prediction of the Sharing Rate of Airport Land Lateral Flow in Chengdu Metro Line 10 董洋洋}

Yangyang Dong

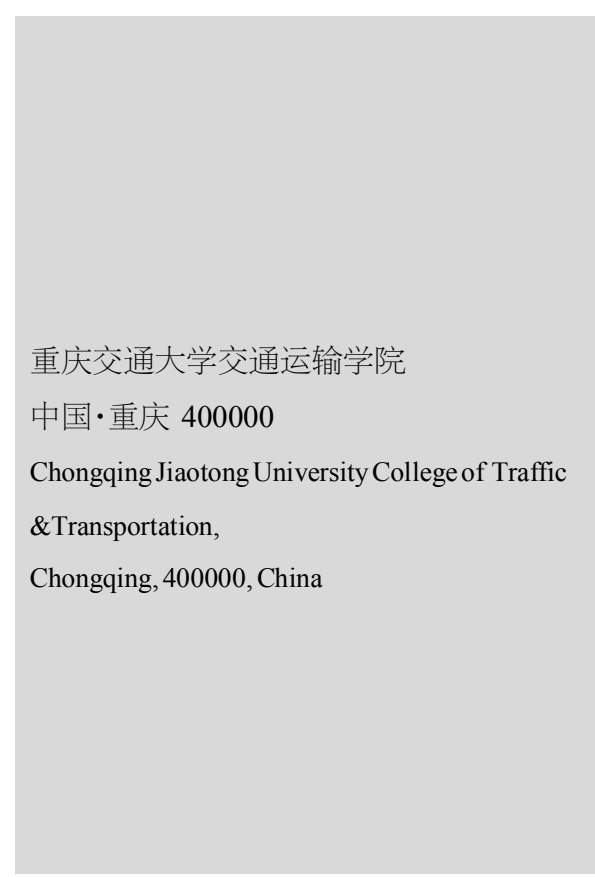

【摘要】作为首条重点服务于成都双流国际机场陆侧客流的城市轨道交通,成都地铁 10 号线一期自开通以来一直在为缓解双流机场陆侧交通的紧张情况起着积极的作用。论文 在此背景下采用被普遍使用的 Logit 模型对地铁在双流机场路侧交通的分担率进行预测, 模型中将极大似然估计法标定参数的方法改进为采用层次分析法来确定模型中特性指标 的参数, 预测地铁 10 号线一期对双流国际机场陆侧交通的分担率水平。

【Abstract】The first phase of Chengdu Metro Line 10 is the first city rail transit in Chengdu city, which is to chiefly serve the landside passenger flow of Chengdu Shuangliu International Airport. Since it's opened, it has been playing an significant role in alleviating the tension of the landside traffic at the airport. Under the background, this passage uses the Logit model which is widely used to predict the share rate of subway in the aspect of landside flow of Shuangliu International Airport. In the model, the maximum likelihood estimate is replaced by the analytic hierarchy process to obtain the parameter of characteristic index for forecasting the share rate of subway in landside flow of airport.

【关键词】分担率; 预测; Logit 模型; AHP

【Keywords】the share rate; prediction; Logit model; AHP

【DOI】10.36012/etr.v2i4.1720

\section{1 引言}

目前,通往机场与城市间的公交方式有常规公交、机场大 巴、出租车、网约车、机场轨道线和铁路等,除公共交通外还包 括部分私人小汽车、单位通勤车等。在轨道交通未引入机场陆 侧地面交通方式时，连接机场和市区的公交方式多是上述形 式的汽车, 但是随着这些汽车数量日益增多, 机场区域的道路 显得十分拥堵。

轨道交通本身具有高速、运量大、环保、准时等众多特点 和强大竞争力, 当其加入机场陆侧地面交通系统后, 显然将对 到离机场旅客具有很大吸引力, 对缓解地面交通压力有积极 作用。机场轨道交通被规划开通运营的主要目的是服务城市 市区与航空港之间的客流。为了分析成都地铁 10 号线开通以 来对地面交通造成的影响，论文将参考已有相关文献对机场 客流及其在机场陆侧交通的分担率作出预测。

\section{2 国际研究历史和现状}

国际对旅客进出机场的交通方式选择行为研究较早,主 要是利用非集计模型对各个进出机场的交通方式的客流预
测。Phang ${ }^{[1]}$ 最早将 ML 模型(Multinomial Logit Model) 应用于航 空出行者在机场陆侧地面交通方式的选择分析。Jani c $^{[2]}$ 探讨 了潜在的轨道交通交通以减轻环境和社会负担的地面接人系 统的机场。姚晏斌阳以北京首都机场为研究对象,建立了机场 陆侧交通客流的生成模型，采用排队论、Logit 模型等方法对 轨道交通引入首都机场后对其他交通方式的分流情况进行分 析预测。

\section{3 双流机场客流总量预测}

\section{1 双流机场现状分析}

成都双流国际机场(以下简称“双流机场”)地处成都双流 城区西南方向,距成都市区约 $16 \mathrm{~km}$ 。根据成都市交通运输委 员会在其官网上的公告,双流机场扩能后将能满足年 6000 万 人次的旅客吞吐量运输需求。在预计的双流机场年度 6000 万 人次的吞吐量中,必将产生巨大的陆侧客流,这些客流在机场 陆侧集疏。毫无疑问，这一部分客流将对双流机场陆侧交通产 生巨大冲击，使本身就不容乐观的双流机场陆侧地面交通情 况陷入更加紧张的局面, 甚至将导致一连串的交通问题。在此 前提下,2017 年 9 月成都地铁 10 号线一期作为专服务于双 
实验与研究 Experiments and Research

流机场客流的轨道交通, 正为缓解双流机场陆侧交通紧张情 况起着重要的分流作用。

\section{2 双流机场客流总量预测}

此部分在参考既有文献的基础上再结合双流机场实际的 具体情况, 对将双流机场特定时间里客流总量进行预测, 为下 文研究计算地铁 10 号线对机场陆侧具体分担量提供客流量 数据。

3.2 .1 对双流机场的分析

在对机场客流出行生成预测中,其日均客流总量 $Q$ 为

$$
Q=q_{\text {旅客 }}+q_{\text {迎送 }}+q_{\text {工作 }}
$$

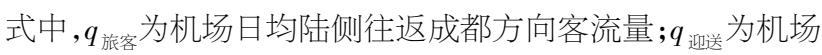

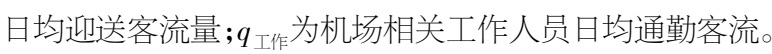

3.2 .2 客流总量的预测过程及结果

对双流机场陆侧日均客流总量预测公式进行整理,即

$$
\begin{gathered}
q_{\text {旅客 }}=\frac{Q_{\mathrm{p}} \times(1-\partial) \times(1-\gamma)}{365} \\
q_{\text {迎送 }}=\frac{Q_{\mathrm{p}} \times(1-\partial) \times \beta}{365} \\
q_{\text {迎送 }}=(x \theta+y) \times 2
\end{gathered}
$$

式中, $Q_{\mathrm{p}}$ 为规划的机场年度航空吞吐量; $\partial$ 为经机场中转的旅 客比例; $\beta$ 为迎送比/系数; $\gamma$ 为非往返机场与成都方向的旅客 比例; $\theta$ 为机场服务人员通勤比; $x$ 为机场的服务人员数; $y$ 为 机场相关工作人员。

根据机场客流的组成情况, 将式(2)、式(3)、式(4)代入 式(1)可得到双流机场日均客流总量,即

$$
Q=\frac{Q_{\mathrm{P}} \times(1-\partial)}{365} \times[(1-\gamma)+\beta]+(\theta x+y) \times 2
$$

\section{4 双流机场客流出行方式预测}

\subsection{Logit 模型各参数的确定}

针对成都地铁 10 号线, 论文以旅行时间、旅行费用、服务 间隔时间、行李处理的便捷性、舒适性共 5 种因素作为方式间 评价指标, 即这 5 各因素在预测分担率水平中的 Logit 模型里 分别表示为 $X_{i}(i=1,2,3,4,5)$ 。

就双流机场陆侧现有地面交通方式而言，论文主要考虑 地铁、机场大巴、出租车、网约车、私家车。在此基础上, 针对 这 5 种交通方式采用两两比较法对进出机场乘客进行调查, 对以上提到的 5 种因素进行不同程度的比较, 以此来获得出 行者选择不同交通方式到离机场时不同特性指标值的影响权 重值。

对于乘坐地铁 10 号线到离双流机场的乘客而言, 根据层 次分析法计算得到两两比较判断矩阵 $\boldsymbol{A}$ 为

$$
\boldsymbol{A}=\left[\begin{array}{ccccc}
1 & 1 / 4 & 1 & 1 / 3 & 3 \\
4 & 1 & 6 & 2 & 4 \\
1 & 1 / 6 & 1 & 1 / 7 & 1 / 3 \\
3 & 1 / 2 & 7 & 1 & 5 \\
1 / 3 & 1 / 4 & 3 & 1 / 5 & 1
\end{array}\right]
$$

根据层次分析法, 可计算得到权重系数向量,即

$$
\boldsymbol{W}=\left[\begin{array}{lllll}
0.119 & 0.413 & 0.061 & 0.318 & 0.089
\end{array}\right]^{\mathrm{T}}
$$

进行一致性检验, 通过计算得到一致性指标, 即

$$
\begin{aligned}
& \lambda_{\max }=5.43 \\
& \text { C.I. }=0.11
\end{aligned}
$$

查阅平均随机一致性指标表, 当 $n=5$ 时, R.I. $=1.12$, 可得 到一致性比例,即

$$
\text { C.R.=C.I./R.I. }=0.096<0.1
$$

因此, 所得到的结果的一致性可以接受, 得到地铁 10 号 线各影响因素的权重 $\boldsymbol{W}$ 可用作本模型中特性指标值的权重 进行分担率预测。同理, 可以计算得到乘坐机场大巴、出租车、 网约车、私家车到离双流机场权重向量, 计算后结果如下:

$$
\begin{aligned}
& \boldsymbol{W}_{\text {机场大巴 }}=\left[\begin{array}{lllll}
0.077 & 0.308 & 0.111 & 0.214 & 0.289
\end{array}\right]^{\mathrm{T}} \\
& \boldsymbol{W}_{\text {出租车 }}=\left[\begin{array}{lllll}
0.182 & 0.068 & 0.099 & 0.373 & 0.279
\end{array}\right]^{\mathrm{T}} \\
& \boldsymbol{W}_{\text {网约车 }}=\left[\begin{array}{lllll}
0.119 & 0.413 & 0.061 & 0.318 & 0.089
\end{array}\right]^{\mathrm{T}} \\
& \boldsymbol{W}_{\text {私家车 }}=\left[\begin{array}{llll}
0.284 & 0.045 .104 & 0.293 & 0.275
\end{array}\right]^{\mathrm{T}}
\end{aligned}
$$

对以上所得到的结果进行检验, 其一致性均小于 0.1 , 得 到的权重可以作为模型中特性指标的权重进行使用。

\subsection{Logit 模型特性指标值的确定}

由于旅行时间、服务间隔时间与效用值成负相关的关系， 旅行时间、服务间隔时间的特性值同理取得。对于行李处理 的便捷性和舒适性的特性值, 参考文献取得, 具体情况如表 1 所示。

表 1 双流机场陆侧交通方式特性指标值

\begin{tabular}{c|c|c|c|c|c}
\hline 交通方式 & 旅行时间 & 旅行费用 & 服务间隔时间 & 便捷性 & 舒适性 \\
\hline 地铁 & 4 & 4 & 3 & 2 & 1 \\
\hline 机场大巴 & 1 & 3 & 1 & 3 & 2 \\
\hline 出租车 & 2 & 1 & 4 & 4 & 2 \\
\hline 网约车 & 2 & 2 & 4 & 4 & 3 \\
\hline 私家车 & 2 & 3 & 4 & 4 & 4 \\
\hline
\end{tabular}

\section{3 地铁对地面交通分担率的预测结果}

通过对 Logit 模型中地铁、机场大巴、出租车、网约车、私 家车 5 种交通方式的特性指标及其参数的确定, 效用值 $V_{i}(i=$ $1,2,3,4,5)$ 为以上 5 种因素的线性函数, 即

$$
V_{i}=\theta_{1} X_{\mathrm{i} 1}+\theta_{2} X_{\mathrm{i} 2}+\theta_{3} \mathrm{X}_{\mathrm{i} 3}+\theta_{4} \mathrm{X}_{\mathrm{i} 4}+\theta_{5} X_{\mathrm{i} 5}
$$

由此可以得到 5 种交通工具各自的效用值。然后再根据 Logit 模型中

(下转第 169 页) 


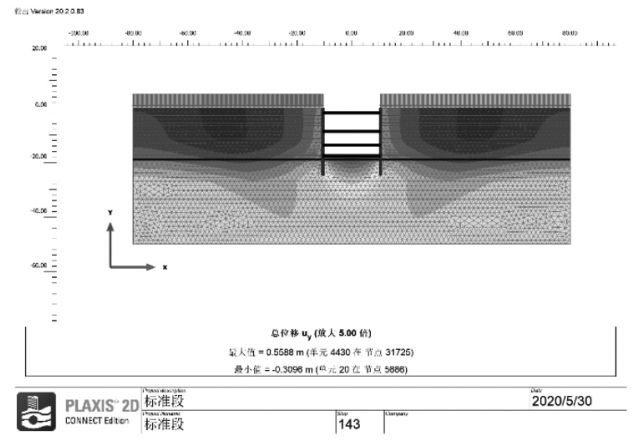

图 5 基坑开挖完成的总位移图

将每一个施工阶段对应的工况反映到模型的变化中, 可得到 其中的一个施工步的分析结果，以及连续施工情况下整个模 型的系统响应 ${ }^{[4]}$ 。对应到 PLAXIS 软件中, 主要是对每一个施 工阶段进行开挖土层的冻结、相应支护结构的激活(包括接触 关系）、荷载的激活与冻结、土层水力条件的修改等, 如果考虑 坑底土层加固等工程措施, 还需要修改对应土层的材料属性。 总之, 基坑开挖分析是一个施工过程的模拟, 必须注重施工顺 序对整体工程系统的影响。在添加固结分析阶段, 选择加载方 式为最小的孔压, 即模拟土体中孔隙水压力消散至某一固定 值时的土体固结情况。将最小孔压值设定为土体的压缩系数,
即模拟当土体完全固结时的固结情况。

基坑支护结构除了要达到快速建模之外, 还要注重简化 结构的主要受力体系, 采用恰当的结构单元, 以达到高效、准 确的求解分析。同时,对地下水控制的合理分析、孔隙水压力 的准确评估, 也关系到土层力学行为及结构受力情况的变化。 为此,本文对挡土结构、结构与土层相互作用、内支撑系统及 针杆系统的模拟做了系统性介绍。此外，在施工过程模拟当 中, 要注意实际施工过程与模型分析工况的对应和吻合, 以利 用数值分析结果对施工过程给予比较准确的指导 ${ }^{[5]}$ 。

\section{参考文献}

[1]左殿军,史林,李铭铭,等.深基坑开挖对邻近地铁隧道影响数值 计算分析[J].岩土工程学报,2014,36(S2):391-395.

[2]刘小丽,马悦,郭冠群,等.PLAXIS2D 模拟计算基坑开挖工程的 适用性分析 [J].中国海洋大学学报(自然科学版),2012,42(4):19-25.

[3]付先进,林作忠. 基于 plaxis 的超深基坑开挖弹塑性有限元数 值计算与分析[J].中国水运(下半月),2010,10(4):190-192.

[4]姚远. 基于 PLAXIS 的基坑开挖模拟研究 [J].低温建筑技术, 2019,41(6)93-95.

[5]曹文峰.连续墙支护深基坑开挖过程有限元分析 [J].黑龙江工 程学院学报,2019,33(6):24-27.
（上接第 166 页）

$$
P_{i}=\frac{\exp \left(\sum_{k=1}^{K} \theta_{h} X_{i k}\right)}{\sum_{j} \exp \left(\sum_{k=1}^{K} \theta_{k} X_{i k}\right)}
$$

针对论文考虑双流机场陆侧 5 种地面交通方式用式 (16) 可得各效用值, 具体计算过程和结果如下:

$$
\mathrm{V}_{\text {地铁 }}=0.119 \times 4+0.413 \times 4+0.061 \times 3+0.381 \times 2+0.089 \times 1=0.306
$$

同理可得 $V_{\text {机场大巴 }}=2.355, V_{\text {出租车 }}=2.876, V_{\text {网约车 }}=3.061, V_{\text {私家车 }}=$ 3.342 。根据以上求得的 5 种交通方式的效用值, 对双流机场 陆侧交通方式 5 种主要交通方式进行分析，通过如下计算可 以得到地铁 10 号线的分担率预测值:

$$
\begin{aligned}
P_{\text {地铁 }}= & \exp \left(V_{\text {地铁 }}\right) /\left[\exp \left(V_{\text {地铁 }}\right)+\exp \left(V_{\text {机场大巴 }}\right)+\exp \left(V_{\text {出租车 }}\right)\right. \\
& \left.+\exp \left(V_{\text {网约车 }}\right)+\exp \left(V_{\text {私家车 }}\right)\right]=21.08 \%
\end{aligned}
$$

同理计算得到其他 4 种交通方式的分担率，得到地铁的 分担率为 $21.08 \%$, 机场大巴为 $10.68 \%$, 出租车为 17.96 , 网约 车为 21.63 , 私家车为 28.65 。

地铁和机场大巴两者共同分担的旅客共占约 $32 \%$, 出租 车和网约车两者共同分担的旅客占约 $40 \%$ 。结合此数据预测 2018 年和当机场吞吐量达到 6000 万人次时，当地铁对双流
机场陆侧一直保持在目前预测的分担率的情况下,2018 年成 都地铁 10 号线对双流机场陆侧日均分担量为 486613 人次; 当机场吞吐量达到 6000 万人次时, 成都地铁 10 号线对双流 机场陆侧日均分担量为 57952 人次。

\section{5 结语}

论文在对成都双流机场特定年的吞吐量进行预测的基础 上，使用 Logit 模型对成都地铁 10 号线一期对双流机场陆侧 交通分担率进行预测，模型中采用层次分析法来确定模型中 特性指标的参数;下一步可以对各个权重进行进一步的更新, 以提高分担率预测精准度; 得到预测分担率后, 再对地铁的具 体分担量进行预测。

\section{参考文献}

[1]Phang S Y.Strategic development of airport and rail infrastructure: the case of Singapore[J]. Transport Policy, 2003,10(1):27-33.

[2]Janić M.Light Rail Rapid Transit systems for more sustainable ground accessibility of airports[J]. Transportation Planning and Technology,2011,34(6):569-592.

[3]姚晏斌. 大容量机场轨道交通对陆侧交通的分流预测 [D]. 天 津:中国民航大学,2006. 